\title{
Prognostic value of FDG-PET scans at diagnosis in small cell lung cancer
}

\author{
Rabih Said ${ }^{1}$, J une Koshy² ${ }^{\text {, Sanaa Rizk }}{ }^{1}$, Raymond ElSoueidi ${ }^{1}$, Philip Friscia ${ }^{1}$, Arnold Brenner ${ }^{2}$ \\ 1. Department of Hematology/Oncology, Staten Island University Hospital, Staten Island, NY, USA. 2. Department of \\ Radiology, Staten Island University Hospital, Staten Island, NY; Department of Nuclear Medicine, Albert Einstein College \\ of Medicine, USA.
}

Correspondence: Rabih Said. Address: Internal Medicine department-Oncology division, The University of Texas Health Science Center, Houston, TX, USA. E-mail: rabihh_said@yahoo.com

Received: August 8, 2013

Accepted: September 18, 2013 Online Published: September 29, 2013

DOI : $10.5430 / j b g c . v 4 n 1 p 21$

URL: http://dx.doi.org/10.5430/jbgc.v4n1p21

\section{Abstract}

Background: Small cell lung carcinoma (SCLC) is one of the most aggressive solid tumors. The predictive and prognostic role of positron emission tomography (PET) scans in SCLC is under investigation and is yet to be determined.

Method: We retrospectively analyzed the correlation between overall survival and 2-[18F]-fluoro-2-deoxy-d-glucosePET (FDG-PET) results at diagnosis. We also introduced the concept of the total standardized uptake value (SUV) as a possible biomarker for the total burden disease. In addition, we proposed a new staging concept using PET scan based on whether tumor uptake is or is not limited to parenchymal hemithorax.

Results: Between March 2004 and February 2009, 46 patients with histologically confirmed SCLC were included in the analysis. Thirty patients were found to have Eastern Cooperative Oncology Group (ECOG) Performance Status $\leq 2$, and most $(65 \%, \mathrm{n}=30)$ of them had limited stage disease using conventional clinical staging criteria. There was a fair correlation between PET results and conventional staging by CT scan (kappa =0.330). Although there was a trend toward upstaging by PET, it was not predictive of survival. There was a direct correlation between total SUV and maximum SUV and overall survival (hazard ratio $[\mathrm{HR}]=1.003$ and 1.085, respectively).

Conclusion: PET scan results at diagnosis could play an important role in the management of SCLC. Total SUV could represent a good biomarker for the disease burden in SCLC. Further prospective studies are needed to clarify the application of total SUV in SCLC.

\section{Key words}

Standardized uptake value (SUV), Small cell lung cancer, PET-scan

\section{I ntroduction}

2-[18F]-fluoro-2-deoxy-d-glucose (FDG) positron emission tomography (PET) is a functional imaging study that plays a major role in cancer management. Its clinical application has been validated in the diagnosis, staging, prognosis and response to therapy in many cancers including lymphoma ${ }^{[1]}$, breast cancer ${ }^{[2]}$, lung adenocarcinoma ${ }^{[3]}$ and other solid tumors ${ }^{[4]}$. 
The uptake of FDG by cancer cells depends on multiple factors such as level of glucose metabolic activity, levels of glucose transporters (mainly 1 and 3) and the expression of hexokinase II and glucose-6- phosphatase ${ }^{[5-9]}$. Because the presence of these factors can differ among different histologic types of cancer cells, there may be diverse clinical applications for FDG-PET in different cancer subtypes. The ultimate result of this test is the measurement of labeled glucose uptake by cancer cells as a marker of metabolic tumor activity, tumor grading, viability and aggressiveness.

The role of FDG-PET in non-small cell lung cancer (NSCLC) has been widely studied, with a trend to upstaging compared to conventional CT scans along with ${ }^{[10-19]}$ a change in clinical management ${ }^{[20-25]}$. In fact, the intensity of FDG uptake in NSCLC, as measured by highest standard uptake value $\left[\mathrm{SUV}_{\max }\right]$ has also been shown to correlate with prognosis ${ }^{[26]}$. The role of FDG-PET in small cell lung cancer (SCLC) has not, however, been determined. SCLC is one of the most aggressive solid tumors; therefore, the cancer cells may be expected to have a high FDG uptake. Preliminary reports have indicated that FDG-PET might have a role in clinical staging and prognosis after chemotherapy ${ }^{[27-29]}$.

The primary endpoint of this study is to report any correlation between FDG uptake at diagnosis and overall survival. Our secondary endpoint includes its role in staging compared to the conventional CT scan staging. We also introduce the

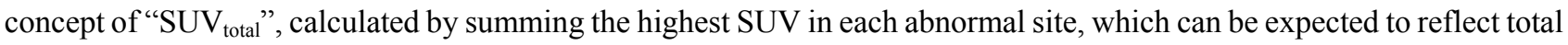
tumor burden and tumor grade.

\section{Methods}

\subsection{Patient selection}

All patients with pathologically confirmed SCLC with FDG-PET scanning performed at diagnosis and treated at our institution between March 2004 and February 2009 were retrospectively identified. Demographic and clinical characteristics were collected from the tumor registry database and the medical records of each patient. The clinical staging of each patient was determined by the treating physicians (medical oncologist, radiation oncologist and radiologist) as appropriate and was determined by clinical examination and conventional CT scan and brain MRI. The clinical staging is divided into limited- and extensive-stage based on whether tumor can or cannot be encompassed within a tolerable radiation therapy port. Our proposed staging by PET scan is divided into limited- and extensive-stage based on whether tumor uptake is or is not limited to parenchymal hemithorax. This study was approved by the Staten Island University Institutional Review Board.

\subsection{FDG-PET scan analysis}

All FDG-PET/CT scans were performed using the Discovery ST PET/CT System (General Electric Healthcare). Patients were instructed to abstain from eating or drinking six hours prior to their appointment (including diabetic medications), limit carbohydrates one day before the exam and abstain from strenuous exercise for twelve hours prior to the test. A blood glucose level was obtained before the exam, and all patient glucose levels were less than $200 \mathrm{mg} / \mathrm{dl}$. Subsequently, an average dose of $12 \mathrm{mCi}$ 18-Flourine FDG was injected intravenously. The patient was then asked to remain in a quiet environment for approximately 45 minutes. A low-dose CT imaging study was then performed from skull base to mid-thigh. A PET scan was then performed immediately after acquiring the CT. Approximately 5-6 bed positions were performed with an acquisition time of $5 \mathrm{~min}$ for each, with imaging from the skull base to mid-thigh. Post-processing was performed using a volumetric PET/CT protocol. Studies were interpreted on a General Electric Xeleris functional imaging workstation.

The total number of FDG avid sites, $\mathrm{SUV}_{\max }$, for each site, total SUV and mean SUV were obtained. The total SUV was obtained by summing the $\mathrm{SUV}_{\max }$ of all sites. The mean SUV was then calculated by dividing the total SUV by the total number of sites. 


\subsection{Statistical analysis}

The following variables were analyzed: age, gender, Eastern Cooperative Oncology Group (ECOG) performance status, clinical staging and staging by PET as proposed. Means were calculated for continuous variables and frequencies were calculated for categorical variables. Overall survival (OS) was considered as the time in months from the date of initial diagnosis to the date of last contact or death. The survival curves by stage (limited vs. extensive) were compared using the log-rank test. The estimated survival curves using the product-limit method and stage (limited, extensive) were compared using the log-rank test. The association among continuous measurements (total SUV, mean SUV, maximum SUV) and survival were examined using Cox regression analysis. The kappa statistic was calculated to measure the agreement between CT scan and PET scan for disease stage.

All statistical analyses were conducted using SAS 9.2 software (SAS Institute Inc., Cary, NC).

\section{Results}

Overall, 46 patients were found to be eligible for this study analysis. The clinical and demographic characteristics are summarized in Table 1.

Table 1. Clinical demographics of the patient at diagnosis

\begin{tabular}{|c|c|c|c|c|c|c|c|c|c|c|}
\hline \multirow{2}{*}{$\begin{array}{l}\text { Age } \\
\text { (Mean, Range) }\end{array}$} & \multicolumn{2}{|c|}{ Gender } & \multicolumn{6}{|c|}{ PS (ECOG) } & \multicolumn{2}{|c|}{ Clinical Stage } \\
\hline & Female & Male & $\mathbf{0}$ & 1 & 2 & 3 & 4 & Unknown & Limited & Extende \\
\hline 69.9 [49-87] & $25(54.4)$ & $21(45.6)$ & - & $27(58.7)$ & $3(6.5)$ & - & $1(2.2)$ & $15(32.6)$ & $30(65.2)$ & $16(34.8)$ \\
\hline
\end{tabular}

Nearly two-thirds of our patients $(\mathrm{n}=30,65.2 \%)$ had limited disease as determined by clinical staging. Among them, two-thirds (20 out of 30) had limited stage disease by FDG PET imaging and the other one-third (10 out of 30) had extensive disease. On the other hand, 16 out of 46 had extensive disease as determined by the conventional staging system and among these 16 patients, only 11 patients were deemed to have extensive stage disease by PET. The correlation between the two methods of staging was fair (kappa 0.33) (see Table 2).

Table 2. Correlation between the clinical staging and the PET staging

\begin{tabular}{lllll}
\hline Clinical Stage & \multicolumn{3}{c}{ PET Stage } & Kappa (K) \\
\cline { 2 - 4 } Frequency (Percent) & Limited & Extended & Total & $\mathbf{0 . 3 3 0 1}$ \\
\hline Limited & 20 & 10 & 30 & \\
Extended & 5 & 11 & 16 \\
Total & 25 & 21 & 46 & \\
\hline
\end{tabular}

Table 3. SUV measurement of the patients

\begin{tabular}{llllll}
\hline SUV measurement, $\mathbf{N}=\mathbf{4 6}$ & Mean & $\mathbf{9 5 \%}$ CI & Range & HR (death) & P-value \\
\hline SUV $_{\text {mean }}$ & 111.6 & $236.0-459.2$ & $5.2-846.0$ & $0.999[0.842-1.156]$ & .9922 \\
SUV $_{\text {max }}$ & 13.1 & $2.1-24.1$ & $2.8-30.7$ & $1.085[1.007-1.169]$ & $<.0313$ \\
SUV $_{\text {total }}$ & 8.5 & $2.8-14.2$ & $2.6-16.0$ & $1.003[1.001-1.005]$ & $<.0003$ \\
\hline
\end{tabular}

The univariate analysis showed that OS was correlated, as expected, with the clinical staging with a median OS of 12.3 months for extensive disease patients vs. 24.3 months for limited stage patients $(p=.02)$ (see Figure 1). In contrast, our proposed staging system determined by PET scanning results was not correlated with OS (see Figure 2). Interestingly, we found a strong negative correlation between $\mathrm{SUV}_{\text {total }}$ and $\mathrm{OS}$. The higher the value for SUV total the shorter was survival, with a hazard ratio HR of $1.003(95 \% \mathrm{CI}: 1.001-1.005, p<.0003)$. $\mathrm{SUV}_{\max }$ was also found to be predictive of OS with a HR (death) of 1.085 (95\% CI 1.007-1.169, $p<.0313)$. On the other hand, the $\mathrm{SUV}_{\text {mean }}$ did not correlate with OS (see Table 3). 


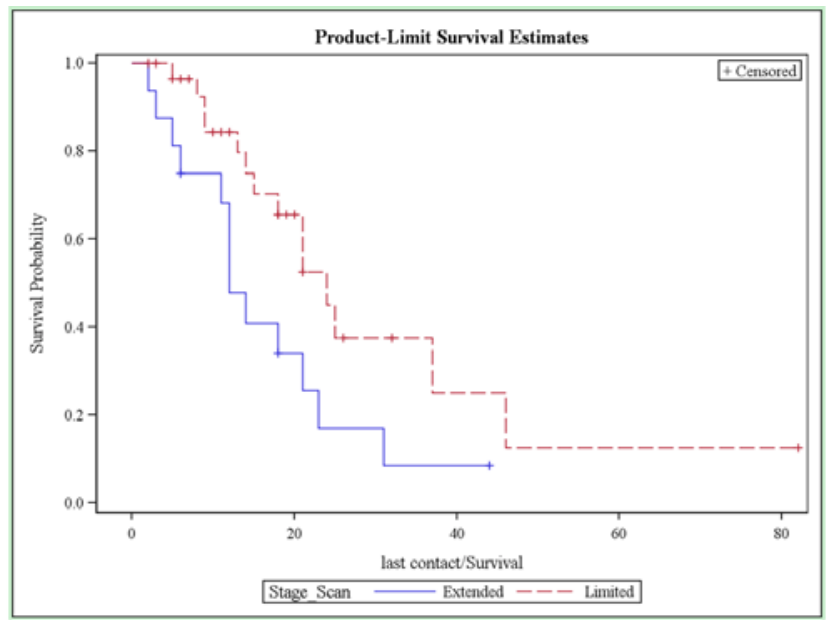

Figure 1. Kaplan Meier curve of the overall survival by clinical staging

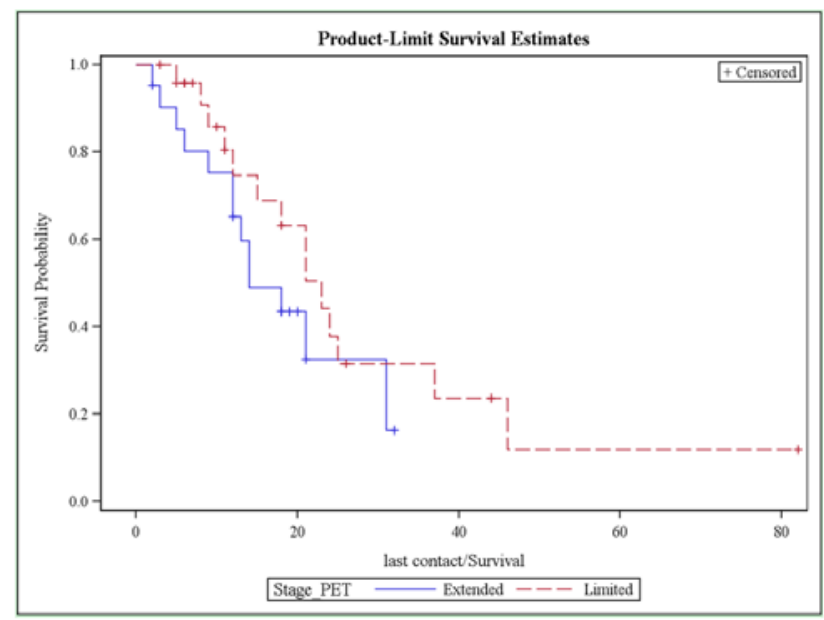

Figure 2. Kaplan Meier curve of the overall survival by PET staging

\section{Discussion}

Compared to other studies, FDG-PET molecular imaging is unique in measuring the metabolic tumor activity and its role in cancer management is still evolving. Our data show that PET can be useful as a predictive biomarker for survival, with significant correlation between $\mathrm{SUV}_{\text {total }}$ and $\mathrm{SUV}_{\max }$ and survival.

Total SUV used as a biomarker is a new concept which is not routinely determined during interpretation of FDG-PET studies. One reason for this may be that it is somewhat time-consuming, particularly in patients with many sites of pathologic FDG uptake, but we hypothesized that it could be an excellent measure of total tumor burden and grade/aggressiveness. In addition, with the fast pace of improvements in information technology, total SUV measurement may be more easily measured routinely in the future.

Our study showed that the SUV mean is not correlated with overall survival and this finding is in accord with previously published data by Joo Lee et al., which showed that a high $\mathrm{SUV}_{\text {mean }}$ value has prognostic value but that low $\mathrm{SUV}_{\text {mean }}$ does $\operatorname{not}^{[30]}$.

Our data also showed that $\mathrm{SUV}_{\max }$ is positively correlated with OS, which is in agreement with previously reported data about the role of $\mathrm{SUV}_{\max }$ as a good predictor factor in NSCLC ${ }^{[31,32]}$.

Accurate staging is the best predictor of survival in cancer, including SCLC. The most commonly used staging system in patients with SCLC is different than that used for other types of tumors. This method divides patients into two groups limited and extensive stage- to determine appropriate therapy and prognosis ${ }^{[33]}$. In our study, PET results showed a slight trend toward higher stage than the staging system currently adopted for clinical decision making. The upstage of PET compared to conventional CT scan results has been previously reported in NSCLC ${ }^{[34]}$. A recent study performed by Xanthopoulos EP et al. evaluating staging with PET in limited stage SCLC also showed that more PET-staged patients presented with nodal metastases. There was also an association with PET staging and survival ${ }^{[35]}$. Recent data suggests that PET can improve staging accuracy and treatment planning in patients with SCLC ${ }^{[36]}$. Our adapted staging criteria established by FDG-PET resulted in a difference of nine months in median OS between limited and extensive stage disease. This difference did not, however, reach statistical significance. The limited number of patients and the treatment based on CT staging could partly explain this discrepant finding. 
Despite the limitations of our retrospective study, it introduced a new concept whereby $\mathrm{SUV}_{\text {total }}$ can be used as a direct measurement of tumor burden and it was statistically significantly correlated with OS. Additionally, this concept has the potential for being applied to other tumor types and may serve as a new marker of prognostic classification. Therefore, further prospective studies are needed to validate our findings in SCLC and other solid tumors.

\section{References}

[1] Friedberg, J.W., Chengazi, V. PET scans in the staging of lymphoma: current status. Oncologist. 2003; 8: 438-447. PMid: 14530496. http://dx.doi.org/10.1634/theoncologist.8-5-438

[2] Quon, A., Gambhir, S.S. FDG-PET and beyond: molecular breast cancer imaging. J Clin Oncol. 2005; 23: 1664-1673. PMid: 15755974. http://dx.doi.org/10.1200/JCO.2005.11.024

[3] Schrevens, L., Lorent, N., Dooms, C., Vansteenkiste, J. The role of PET scan in diagnosis, staging, and management of non-small cell lung cancer. Oncologist. 2004; 9: 633-643. PMid: 15561807. http://dx.doi.org/10.1634/theoncologist.9-6-633

[4] Kubicek, G.J., et al. FDG-PET staging and importance of lymph node SUV in head and neck cancer. Head Neck Oncol. 2010; 2: 19. PMid: 20637102. http://dx.doi.org/10.1186/1758-3284-2-19

[5] Yonekura, Y., et al. Increased accumulation of 2-deoxy-2-[18F]Fluoro-D-glucose in liver metastases from colon carcinoma. J Nucl Med. 1982; 23: 1133-1137. PMid: 6982967.

[6] Minn, H., Joensuu, H., Ahonen, A., Klemi, P. Fluorodeoxyglucose imaging: a method to assess the proliferative activity of human cancer in vivo. Comparison with DNA flow cytometry in head and neck tumors. Cancer. 1988; 61: 1776-1781. http://dx.doi.org/10.1002/1097-0142(19880501)61:9<1776::AID-CNCR2820610909>3.0.CO;2-7

[7] Flier, J.S., Mueckler, M.M., Usher, P., Lodish, H.F. Elevated levels of glucose transport and transporter messenger RNA are induced by ras or src oncogenes. Science. 1987; 235: 1492-1495. PMid: 3103217. http://dx.doi.org/10.1126/science.3103217

[8] Mueckler, M. Facilitative glucose transporters. Eur J Biochem. 1994; 219: 713-725. PMid: 8112322. http://dx.doi.org/10.1111/j.1432-1033.1994.tb18550.x

[9] Yen, T.C., et al. 18F-FDG uptake in squamous cell carcinoma of the cervix is correlated with glucose transporter 1 expression. J Nucl Med. 2004; 45: 22-29. PMid: 14734665.

[10] Bury, T., et al. Staging of the mediastinum: value of positron emission tomography imaging in non-small cell lung cancer. Eur Respir J. 1996; 9: 2560-2564. PMid: 8980969. http://dx.doi.org/10.1183/09031936.96.09122560

[11] Cerfolio, R.J., et al. The role of FDG-PET scan in staging patients with nonsmall cell carcinoma. Ann Thorac Surg. 2003; 76: 861-866. http://dx.doi.org/10.1016/S0003-4975(03)00888-9

[12] Fritscher-Ravens, A., et al. Endoscopic ultrasound, positron emission tomography, and computerized tomography for lung cancer. Am J Respir Crit Care Med. 2003; 168: 1293-1297. PMid: 12904322. http://dx.doi.org/10.1164/rccm.200301-050OC

[13] Kernstine, K.H., et al. PET, CT, and MRI with Combidex for mediastinal staging in non-small cell lung carcinoma. Ann Thorac Surg. 1999; 68: 1022-1028. http://dx.doi.org/10.1016/S0003-4975(99)00788-2

[14] Reed, C.E., et al. Results of the American College of Surgeons Oncology Group Z0050 trial: the utility of positron emission tomography in staging potentially operable non-small cell lung cancer. J Thorac Cardiovasc Surg. 2003; 126: 1943-1951. PMid: 14688710. http://dx.doi.org/10.1016/j.jtcvs.2003.07.030

[15] Saunders, C.A., Dussek, J.E., O'Doherty, M.J., Maisey, M.N. Evaluation of fluorine-18-fluorodeoxyglucose whole body positron emission tomography imaging in the staging of lung cancer. Ann Thorac Surg. 1999; 67: 790-797. http://dx.doi.org/10.1016/S0003-4975(98)01257-0

[16] Valk, P.E., et al. Staging non-small cell lung cancer by whole-body positron emission tomographic imaging. Ann Thorac Surg. 1995; 60: 1573-1581; discussion 1581-1572.

[17] Vansteenkiste, J.F., et al. Lymph node staging in non-small-cell lung cancer with FDG-PET scan: a prospective study on 690 lymph node stations from 68 patients. J Clin Oncol. 1998; 16: 2142-2149. PMid: 9626214.

[18] Vansteenkiste, J.F., et al. FDG-PET scan in potentially operable non-small cell lung cancer: do anatometabolic PET-CT fusion images improve the localisation of regional lymph node metastases? The Leuven Lung Cancer Group. Eur J Nucl Med. 1998; 25: 1495-1501. PMid: 9799345. http://dx.doi.org/10.1007/s002590050327

[19] Vansteenkiste, J.F., et al. Mediastinal lymph node staging with FDG-PET scan in patients with potentially operable non-small cell lung cancer: a prospective analysis of 50 cases. Leuven Lung Cancer Group. Chest. 1997; 112: 1480-1486. PMid: 9404742. http://dx.doi.org/10.1378/chest.112.6.1480 
[20] Bury, T., et al. Whole-body 18FDG positron emission tomography in the staging of non-small cell lung cancer. Eur Respir. 1997; J 10: 2529-2534.

[21] Lewis, P., et al. Whole-body $18 \mathrm{~F}$-fluorodeoxyglucose positron emission tomography in preoperative evaluation of lung cancer. Lancet. 1994; 344: 1265-1266. http://dx.doi.org/10.1016/S0140-6736(94)90753-6

[22] Pieterman, R.M., et al. Preoperative staging of non-small-cell lung cancer with positron-emission tomography. N Engl J Med. 2000; 343: 254-261. PMid: 10911007. http://dx.doi.org/10.1056/NEJM200007273430404

[23] Hicks, R.J., et al. (18)F-FDG PET provides high-impact and powerful prognostic stratification in staging newly diagnosed non-small cell lung cancer. J Nucl Med. 2001; 42: 1596-1604. PMid: 11696627.

[24] Hoekstra, C.J., et al. The value of [18F]fluoro-2-deoxy-D-glucose positron emission tomography in the selection of patients with stage IIIA-N2 non-small cell lung cancer for combined modality treatment. Lung Cancer. 2003; 39: 151-157. http://dx.doi.org/10.1016/S0169-5002(02)00446-4

[25] Schmucking, M., et al. Molecular whole-body cancer staging using positron emission tomography: consequences for therapeutic management and metabolic radiation treatment planning. Recent Results Cancer Res. 2003; 162: 195-202. PMid: 12790335. http://dx.doi.org/10.1007/978-3-642-59349-9_19

[26] Okereke, I.C., et al. Standard uptake value predicts survival in non-small cell lung cancer. Ann Thorac Surg. 2009; 88: 911-915; discussion 915-916. PMid: 19699919. http://dx.doi.org/10.1016/j.athoracsur.2009.05.083

[27] Van Loon, J., et al. Selective nodal irradiation on basis of (18)FDG-PET scans in limited-disease small-cell lung cancer: a prospective study. Int J Radiat Oncol Biol Phys. 2010; 77: 329-336. PMid: 19782478. http://dx.doi.org/10.1016/j.ijrobp.2009.04.075

[28] Azad, A., et al. High impact of 18F-FDG-PET on management and prognostic stratification of newly diagnosed small cell lung cancer. Mol Imaging Biol. 2010; 12: 443-451. PMid: 19921339. http://dx.doi.org/10.1007/s11307-009-0295-Z

[29] Yamamoto, Y., et al. Early assessment of therapeutic response using FDG PET in small cell lung cancer. Mol Imaging Biol. 2009; 11: 467-472. PMid: 19434460. http://dx.doi.org/10.1007/s11307-009-0227-y

[30] Lee, Y.J., et al. High tumor metabolic activity as measured by fluorodeoxyglucose positron emission tomography is associated with poor prognosis in limited and extensive stage small-cell lung cancer. Clin Cancer Res. 2009; 15: 2426-2432. PMid: 19318478. http://dx.doi.org/10.1158/1078-0432.CCR-08-2258

[31] Vansteenkiste, J.F., et al. Prognostic importance of the standardized uptake value on (18)F-fluoro-2-deoxy-glucose-positron emission tomography scan in non-small-cell lung cancer: An analysis of 125 cases. Leuven Lung Cancer Group. J Clin Oncol. 1999; 17: 3201-3206. PMid: 10506619.

[32] De Geus-Oei, L.F., van der Heijden, H.F., Corstens, F.H., Oyen, W.J. Predictive and prognostic value of FDG-PET in nonsmall-cell lung cancer: a systematic review. Cancer. 2007; 110: 1654-1664. PMid: 17879371. http://dx.doi.org/10.1002/cncr.22979

[33] Jett, J.R., Schild, S.E., Kesler, K.A., Kalemkerian, G.P. Treatment of small cell lung cancer: Diagnosis and management of lung cancer, 3rd ed: American College of Chest Physicians evidence-based clinical practice guidelines. Chest. 2013; 143: e400S-419S.

[34] Irion, K.L. ACP Journal Club. PET plus CT was better than conventional methods for correctly upstaging early NSCLC. Ann Intern Med. 2009; 151: JC6-10. PMid: 20008746. http://dx.doi.org/10.7326/0003-4819-151-12-200912150-02010

[35] Xanthopoulos, E.P., et al. Impact of PET staging in limited-stage small-cell lung cancer. J Thorac Oncol. 2013; 8: 899-905. PMid: 23608814. http://dx.doi.org/10.1097/JTO.0b013e31828e8996

[36] Kalemkerian, G.P., Gadgeel, S.M. Modern staging of small cell lung cancer. J Natl Compr Canc Netw. 2013; 11: 99-104. PMid: 23307985 . 